\title{
OPEN Black spicules from a new interstitial opheliid polychaete Thoracophelia minuta sp. nov. (Annelida: Opheliidae)
}

\begin{abstract}
Naoto Jimi ${ }^{1 凶}$, Shinta Fujimoto ${ }^{2}$, Mami Takehara ${ }^{1}$ \& Satoshi Imura ${ }^{1,3}$
The phylum Annelida exhibits high morphological diversity coupled with its extensive ecological diversity, and the process of its evolution has been an attractive research subject for many researchers. Its representatives are also extensively studied in fields of ecology and developmental biology and important in many other biology related disciplines. The study of biomineralisation is one of them. Some annelid groups are well known to form calcified tubes but other forms of biomineralisation are also known. Herein, we report a new interstitial annelid species with black spicules, Thoracophelia minuta sp. nov., from Yoichi, Hokkaido, Japan. Spicules are minute calcium carbonate inclusions found across the body and in this new species, numerous black rod-like inclusions of calcium-rich composition are distributed in the coelomic cavity. The new species can be distinguished from other known species of the genus by these conspicuous spicules, shape of branchiae and body formula. Further, the new species' body size is apparently smaller than its congeners. Based on our molecular phylogenetic analysis using $18 \mathrm{~S}$ and $28 \mathrm{~S}$ sequences, we discuss the evolutionary significance of the new species' spicules and also the species' progenetic origin.
\end{abstract}

Annelida is one of the most ecologically and morphologically diverse group of animals known from both marine and terrestrial environments. Several groups are highly specialised with distinct ecological niches such as interstitial, parasitic, pelagic, or chemosynthetic zones ${ }^{1}$. Like many other animal phyla ${ }^{2-6}$, annelids are known to produce biominerals ${ }^{2}$. Groups such as Serpulidae, Sabellidae, and Cirratulidae, forming calcium encrusted tubes ${ }^{7-9}$, are commonly encountered in the marine environment. However, biominerals produced as a part of the animal body (chaetae, body shields, granule-shaped inclusions, and rod-shaped inclusions) are only sporadically reported from distantly related annelid groups ${ }^{10,11}$, implying their multiple origins.

The family Opheliidae is one of those groups that have biomineralisation-acquired representatives. Species of this family are active burrowers with an elongate and cylindrical body and they are commonly found in sandy or muddy substrates from the intertidal zone to deep-sea floor ${ }^{1}$. The biominerals were reported by Belova \& Zhadan (2011) in several species of the genus Ophelia with rod-like inclusions that are produced by cells floating in the coelom. However, the mineral composition of these inclusions was not investigated ${ }^{12}$.

We found an interstitial opheliid species with rod-like inclusions from Yoichi, Hokkaido, Japan. For its body divided into three regions and absence of lateral eyes ${ }^{13}$, the species is designated to the genus Thoracophelia and we describe this species as Thoracophelia minuta sp. nov. In addition, we investigated the mineral composition of the rod-like inclusions. This is the first report of biomineralization in Thoracophelia. The small size of the new species compared to those of its congeners is also noteworthy. With molecular phylogenetic analysis, we investigated the evolutionary significance of these two topics.

\section{Materials and methods}

Four specimens of opheliid polychaetes were collected from subtidal sand at Yoichi, Hokkaido, Japan (43 $11^{\prime} 59^{\prime \prime}$ N, $140^{\circ} 46^{\prime} 56^{\prime \prime}$ E, Fig. 1A) on 12th March 2019. The sediment sample was vigorously stirred in tap water, and the supernatant was poured through a $32 \mu \mathrm{m}$ mesh plankton net. The extract on the net was immediately emptied in a dish with seawater and sorted under a stereomicroscope. Three specimens for morphological examination were

\footnotetext{
${ }^{1}$ National Institute of Polar Research, 10-3 Midori-cho, Tachikawa, Tokyo 190-8518, Japan. ${ }^{2}$ Research Center for Marine Biology, Graduate School of Life Sciences, Tohoku University, 9 Asamushi, Aomori 039-3501, Japan. ${ }^{3}$ The Graduate University for Advanced Studies, SOKENDAI, 10-3 Midori-cho, Tachikawa, Tokyo 190-8518, Japan. ${ }^{\circledR}$ email: beniimo7010@gmail.com
} 

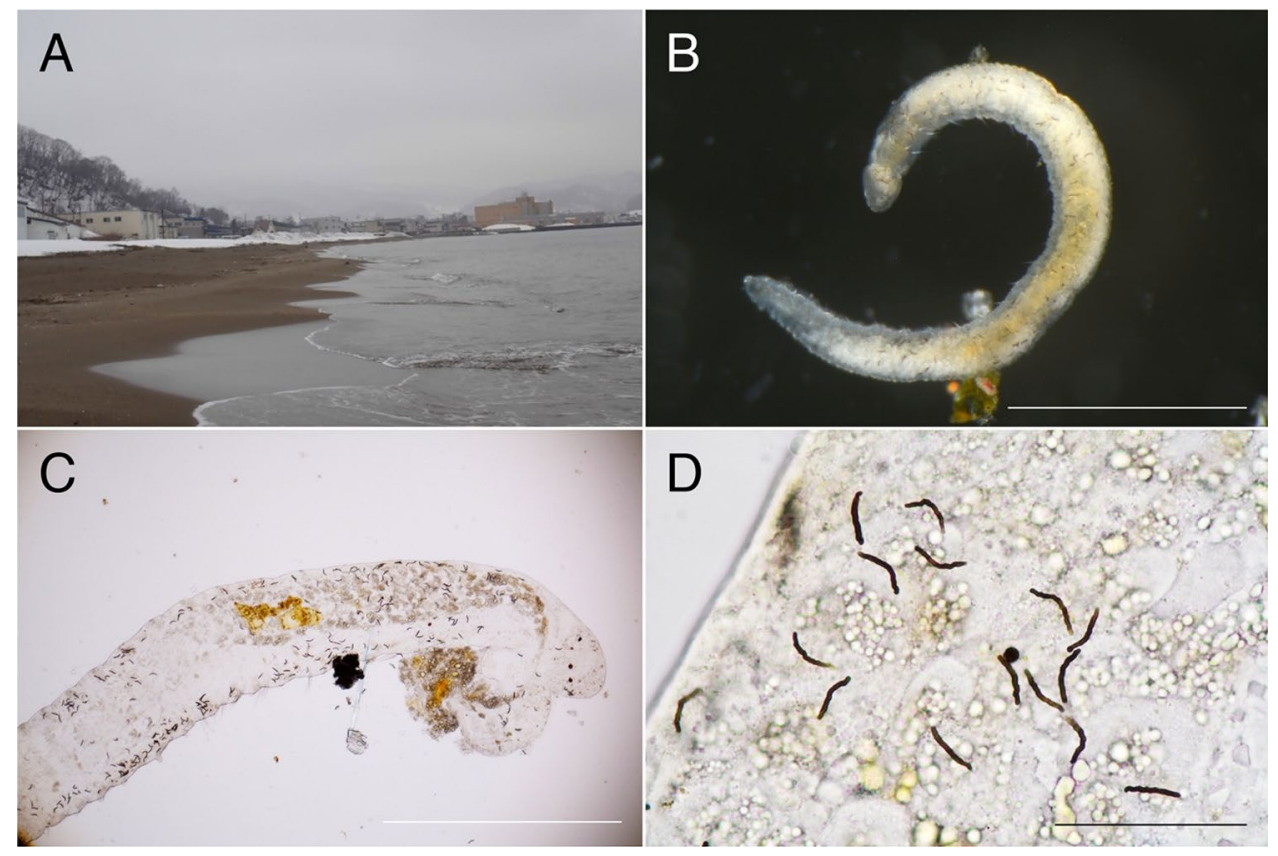

Figure 1. Habitat and live specimen of Thoracophelia minuta sp. nov. (A), the landscape of the type locality, Yoichi. (B), whole body, holotype. (C), Anterior end, paratype. (D), enlarged view of spicules, paratype. Scale bar: B, $0.5 \mathrm{~mm}$; C, $250 \mu \mathrm{m}$; D, $100 \mu \mathrm{m}$. The figure was created with Adobe Illustrator v CS6 and Photoshop v CS6.

fixed in $10 \%$ seawater buffered formalin and preserved in 70\% ethanol, and one specimen for DNA extraction was fixed in 99.5\% ethanol. The three former specimens were observed under stereomicroscopes MZ16, (LEICA, Germany) and E600 (Nikon, Japan). Two of the specimens were used for scanning electron microscope (SEM) observations. They were washed in deionised water, dehydrated in a graded ethanol series, dried in a criticalpoint dryer (HITACHI HCP-2) using liquid $\mathrm{CO}_{2}$, and coated with gold in an ion sputter (HITACHI E-1045). Observations were conducted using an SEM instrument (HITACHI S-3000N).

The observation of major elements was carried out using a scanning electron microscope (SEM; JEOL JSM5900LV), installed with an energy dispersive spectrometer (EDS; X-Max $20 \mathrm{~mm}^{2}$ silicon drift detector processed with AztecOne), at the National Institute of Polar Research, Japan. The samples were placed on an aluminium disc and coated with carbon. The electron beam current was approximately $2 \mathrm{nA}$ at an acceleration voltage of $15 \mathrm{kV}$. The specimens were deposited at the National Museum of Nature and Science, Tsukuba (NSMT) and Invertebrate Collection of the Hokkaido University Museum (ICHUM). The terminology of Opheliidae follows that of Santos et al. ${ }^{14}$.

Genomic DNA was extracted from one specimen (total body) following the methods of Jimi and Fujiwara ${ }^{15}$. The cytochrome $c$ oxidase subunit I (COI), 18S rRNA (18S), and 28S rRNA (28S) genes were amplified and sequenced using the following primer sets: polyLCO (5'-GAYTATWTTCAACAAATCATAAAGATATTGG-3') and polyHCO (5'-TAMACTTCWGGGTGACCAAARAATCA- $\left.3^{\prime}\right)^{16}$; mitchA (CAACCTGGTTGATCCTGC CAGT) and mitchB (TGATCCTTCCGCAGGTTCACCTAC) ${ }^{17}$; and LsudiF (ACCCGCTGAATTTAAGCATA) and D3aR (ACGAACGATTTGCACGTCAG) ${ }^{18}$. The newly obtained sequences were deposited at the DDBJ/ EMBL/GenBank (MW429791, COI gene, 677 base pairs (bp); MW429485, 18 S gene, 1629 bp; MW429484, $28 \mathrm{~S}$ gene, $1010 \mathrm{bp}$ ) (Table 1). The comparative sequences were retrieved from Paul et al. $(2010)^{19}$ (Table 1). All sequences of $18 \mathrm{~S}$ and $28 \mathrm{~S}$ were aligned using MAFFT ver. 7.205 under the E-INS-i strategy ${ }^{20}$. Alignmentambiguous positions were removed using trimAL under the gappyout strategy ${ }^{21}$. The trimmed sequences of the two genes, $18 \mathrm{~S}(1019 \mathrm{bp})$ and $28 \mathrm{~S}(713 \mathrm{bp})$, were concatenated using Kakusan ${ }^{22}$, which recommended a $\mathrm{GTR}+\mathrm{G}$ evolutionary model for each of the genes. A phylogenetic tree was constructed using the maximum likelihood (ML) method in the RAxML-VI-HPC ${ }^{23}$ program. The robustness of the ML tree was evaluated by 1,000 bootstrap pseudo-replicates (-f option). Bayesian inference (BI) analysis was conducted using Mr. Bayes ver. 3.2.2 $2^{24}$, with Markov chains of 10 million generations. The model choice for each partition was also based on the Kakusan results. Run convergence was analysed using Tracer ver. $1.6^{25}$; the first 1 million generations of trees were discarded as burn-in.

For nomenclatural acts, we registered this publication in Zoobank. Zoobank LSID is urn:lsid:zoobank. org:pub:B38565DE-1445-402C-9CC2-4ED5161197C7. 


\begin{tabular}{|l|l|l|}
\hline Species & $\mathbf{1 8 S}$ & $\mathbf{2 8 S}$ \\
\hline Armandia bilobata & DQ779641 & DQ779676 \\
\hline Armandia brevis & KF511818 & KF511838 \\
\hline Armandia maculata & AY040681 & HM746737 \\
\hline Lobochesis bibranchia & AB106266 & - \\
\hline Ophelia bicornis & AF508122 & HM746745 \\
\hline Ophelia neglecta & AF448156 & HM746747 \\
\hline Ophelia rathkei & AF448157 & AY366513 \\
\hline Ophelina acuminata & HM746735 & HM746744 \\
\hline Ophelina cylindricaudata & KF511824 & KF511848 \\
\hline Polyophthalmus pictus & AF448161 & AF185194 \\
\hline Thoracophelia dillonensis & KF511830 & KF511851 \\
\hline Thoracophelia ezoensis & HM746725 & HM746738 \\
\hline Thoracophelia minuta & MW429485 & MW429484 \\
\hline Thoracophelia mucronata & KF511831 & KF511852 \\
\hline Thoracophelia williamsi & KF511832 & KF511854 \\
\hline Neolipobranchius sp. & AY612616 & AY612626 \\
\hline Sclerobregma branchiata & AY612615 & AY612623 \\
\hline & & \\
\hline
\end{tabular}

Table 1. List of opheliids and outgroup species included in the phylogenetic analysis, together with accession numbers in GenBank.

\section{Results}

Observation of biominerals. In the new species, approximately 300 rod-like inclusions were observed in the coelomic cavity filled with body fluid (Fig. 1B-D). They were neither attached to a specific organ nor embedded in tissue and drifted with the body fluid. Our observation of the raw material (without any staining) at $1000 \times$ magnification using light microscopy could not determine whether the rod-like inclusions were intracellular or extracellular structures (Fig. 1C). This point was not clarified by the SEM as well. Although we were able to partly expose the rod-like inclusions by dissecting the body, we could not isolate them or distinguish between associated cells and artefactual presence of tissue. The rod-like inclusions had the following features (Fig. 1D): $i$ ) black colour, ii) approximately $20 \mu \mathrm{m}$ in length, and iii) corrugated rod shape with some of them curved. SEMEDS analysis detected high levels of carbon, oxygen, sulphur, and calcium from spicules, in contrast to chaetae with a high content of carbon, oxygen, and chloride (Fig. 2). However, carbon was sputtered during specimen preparation, and the detected carbon peaks were not reliable.

Molecular phylogenetic analysis. ML and BI analyses recovered the same topology. The monophyly of Opheliidae was inferred with maximum support values (100\% bootstrap support [BS], 1.00 posterior probability [PP]), and the two main clades, the Ophelininae clade and the Opheliinae clade, were also inferred with high support values (93\% BS, 1.00 PP; 99\% BS, 1.00 PP), as in previous studies (Paul et al., 2010). The new species collected in this study, Thoracophelia minuta sp. nov., was a sister species to Thoracophelia ezoensis with high support values (99\% BS, $1.00 \mathrm{PP}$ ) within Opheliidae (Fig. 3).

Taxonomic account. Family Opheliidae Malmgren, 1867.

Genus Thoracophelia Ehlers, 1897.

Thoracophelia minuta sp. nov.

[New Japanese name: sunatsubu-ophelia].

Material examined. Holotype (NSMT-Pol H-837) and paratype (ICHUM-6177) are deposited in the National Museum of Nature and Science, Tsukuba (NSMT). Other specimens were used for DNA extraction and spicule extraction.

Sequences. Sequences were determined from a specimen collected with the type material: COI, $677 \mathrm{bp}$, MW429791; 18S, 1629 bp, MW429485; 28S, 1010 bp, MW429484.

Description of holotype (variation amongst paratypes indicated in parentheses). Preserved material white; color in life transparent. Holotype with gametes. Body $1.6 \mathrm{~mm}$ long $(1.4 \mathrm{~mm}, \mathrm{n}=2), 0.1 \mathrm{~mm}$ width $(0.1 \mathrm{~mm}, \mathrm{n}=2), 25$ chaetigers $(25, \mathrm{n}=2)$. Segmentation not clearly defined. Prostomium pointed, with 4 red eyes $(4, \mathrm{n}=2)$ (Fig. 1C). Peristomium achaetous, cephalic region without chaetigers before cephalo-thoracic constriction (Figs. 1B, 4A). Chaetiger 1 biramous (Fig. 4A). Body formula $5 \mathrm{a}$ (abranchiate) $+20 \mathrm{~b}$ (branchiate) $+0 \mathrm{a}$ (posterior abranchiate) (Fig. 4A). Pygidial funnel short, with 4 cirri of equal size on each side (Fig. 4C). Ventral groove extending from chaetiger 3 to pygidium. No lateral cirri or ridge in chaetiger 10. Noto- and neurochaetae all serrated chaetae (Fig. 4D), 2-3 chaetae per parapodium in chaetigers 1-24, one chaeta per parapodium in chaetiger 25. 


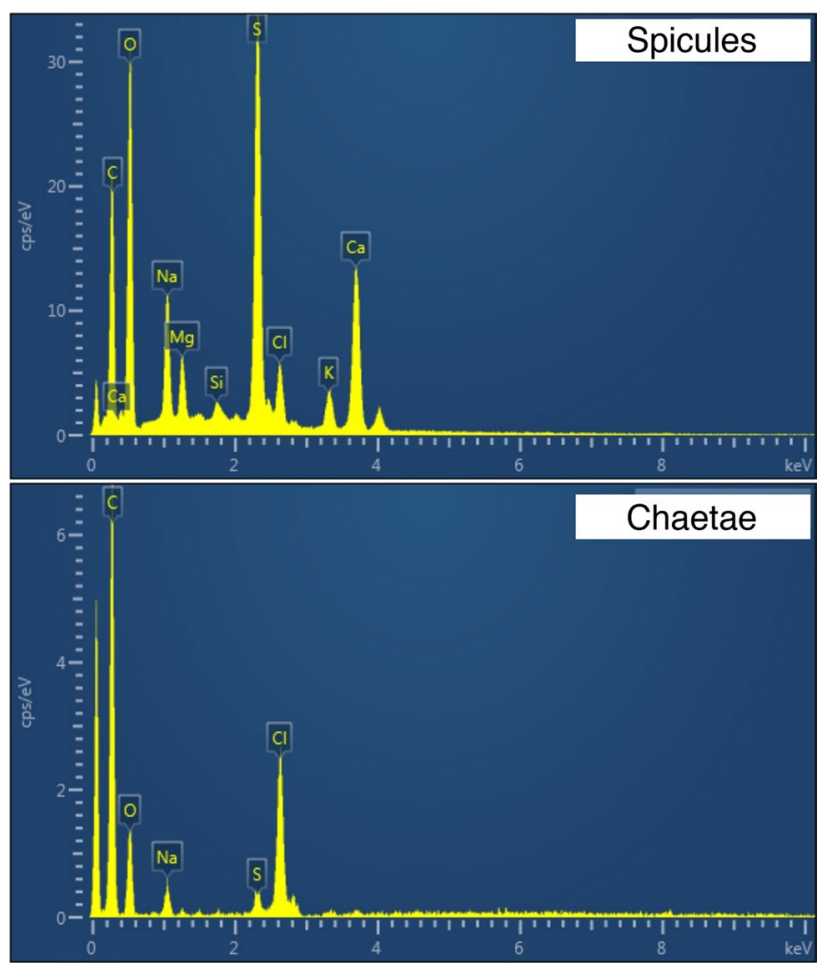

Figure 2. Results of energy-dispersive spectroscopy carried out on two tissue types in Thoracophelia minuta sp. nov. The figure was created with AZtecOne and Adobe Illustrator v CS6.

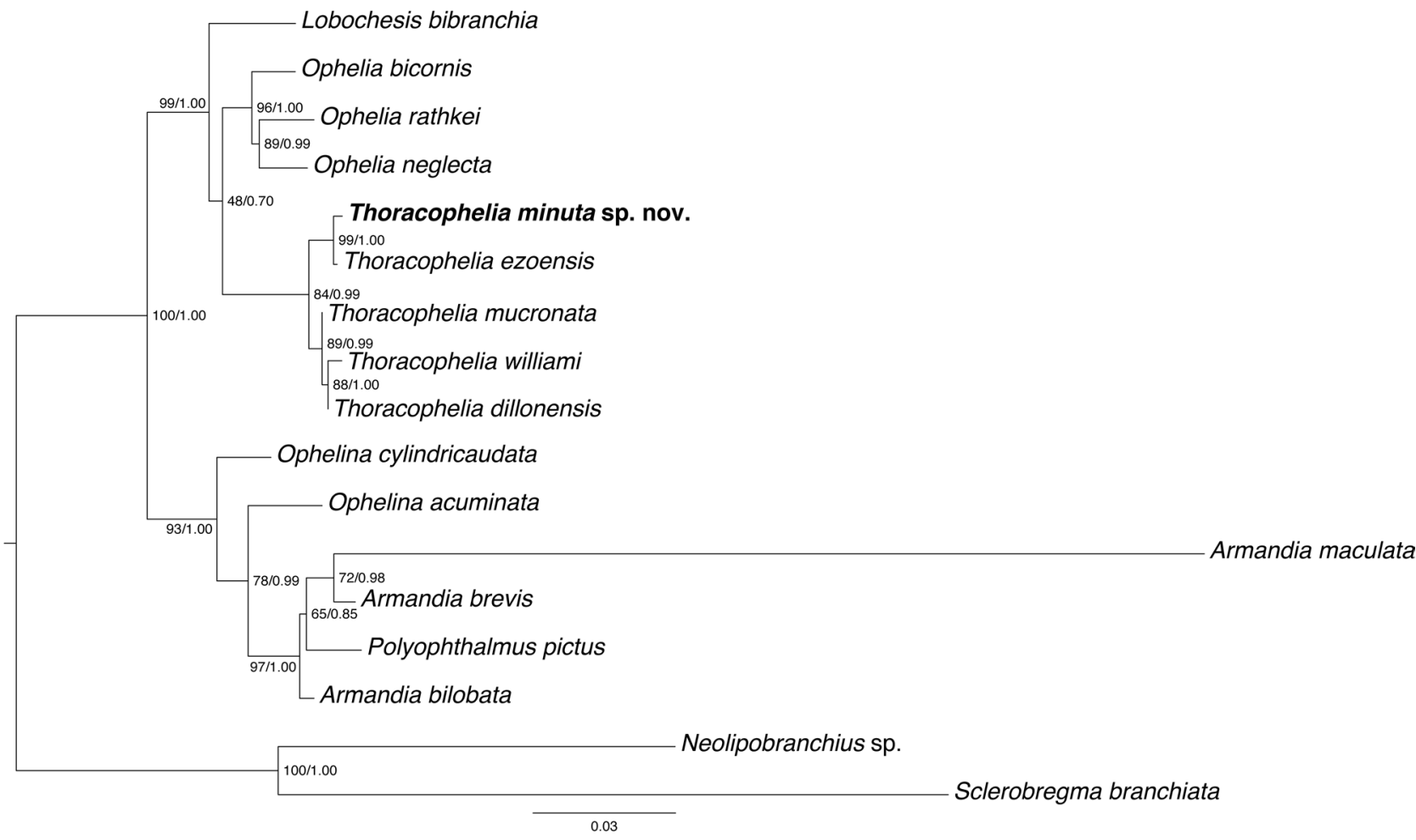

Figure 3. Maximum-likelihood (ML) phylogenetic tree of Opheliidae based on $18 \mathrm{~S}$ and $28 \mathrm{~S}$ sequences. Neolipobranchius sp. and Sclerobregma branchiata were used as 'outgroups' for the rest of the opheliids. Nodal support values (bootstrap support [BS] value) higher than $50 \%$ are indicated on each branch. The figure was created with Adobe Illustrator v CS6. 

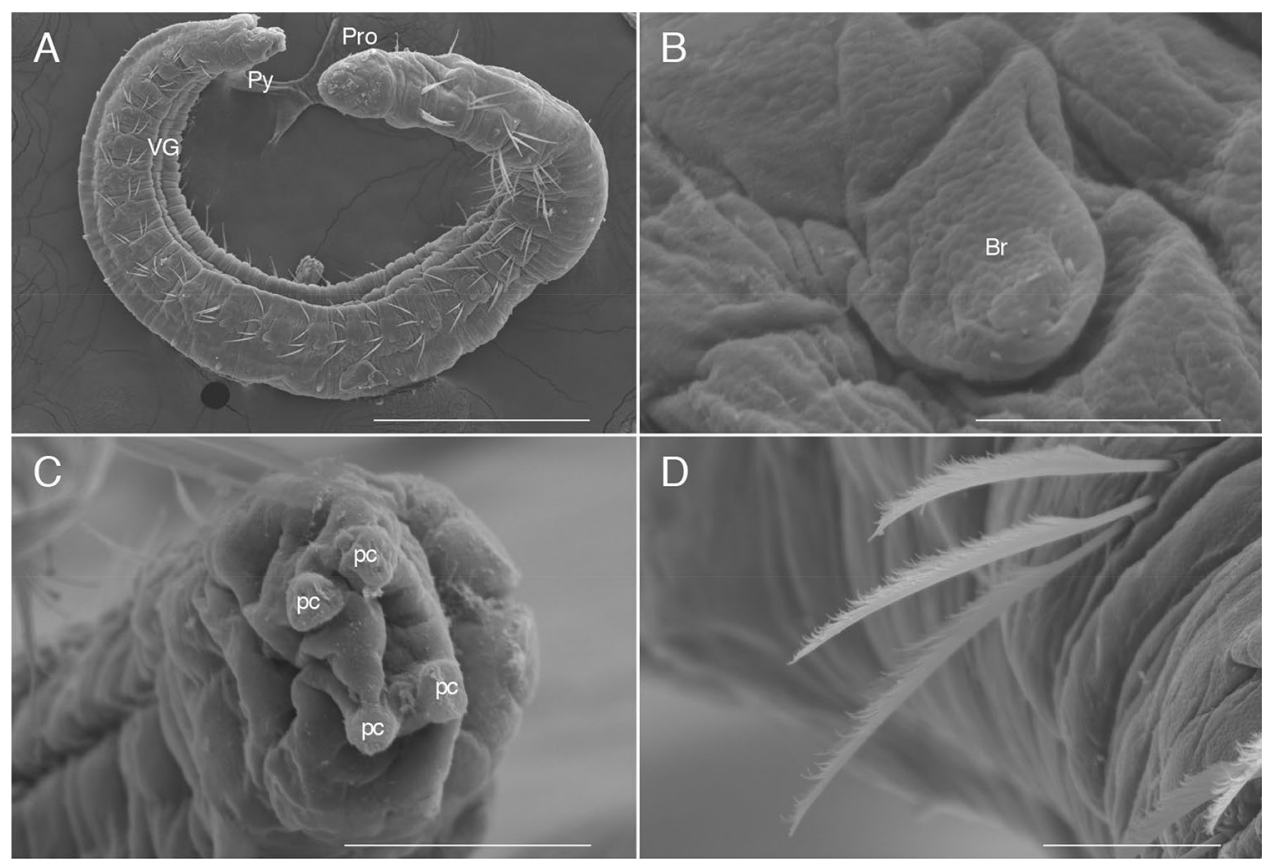

Figure 4. SEM photographs of Thoracophelia minuta sp. nov., paratype. A, whole body. B, branchia. C, pygidium. D, chaetae. Scale bars: A, $300 \mu \mathrm{m} ; \mathrm{B}, 10 \mu \mathrm{m} ; \mathrm{C}, 50 \mu \mathrm{m} ; \mathrm{D}, 20 \mu \mathrm{m}$. Abbreviations: Br, branchia; pc, pygidial cirri; Pro, prostomium; Py, pygidium; VG, ventral groove. The figure was created with Adobe Illustrator v CS6 and Photoshop v CS6.

Noto- and neurochaetae in anterior segments longer than posterior ones. Branchiae simple, hemisphere shape (Fig. 4B). Segmental eyes absent. Oocytes present in the body (Fig. 1B), $10 \mu \mathrm{m}$ in diameter. Body contained many spicules in coelom cavity (Fig. 1B,C,D).

Etymology. The new specific name derives from its minute body.

Habitat and distribution. Specimens of Thoracophelia minuta sp. nov. were collected from the subtidal beach of Yoichi, Hokkaido Prefecture, Japan. The species is only known from the type locality.

Remarks. This species is distinguished from other congeners by the following features: $i$ ) having a minute body (body length approximately $1.5 \mathrm{~mm}$ ), ii) simple hemisphere-shaped branchiae, iii) body formula $5 \mathrm{a}+20 \mathrm{~b}+0 \mathrm{a}$. Known species of Thoracophelia (See Table 1 of Santos et al. 2004 ${ }^{14}$ ) have $i$ ) larger bodies (9-100 mm), ii) branched branchiae, iii) body formula $10-13 a+14-22 b+5-11 a$. The new species has minute body unlike other opheliids. However, since it has eggs, we can judge that it is a small but mature individual.

In Japan, four species of Thoracophelia have been recorded ${ }^{26}$ : Thoracophelia arcticus, T. ezoensis, T. japonicus, T. yasudai. These species have a lateral glandular ridge on chaetiger 10 and branched branchiae. The new species do not have them. For understanding the biodiversity of the Japanese coast, investigation of interstitial species is also needed.

\section{Discussion}

Among biominerals produced by animals, spicules are one of the common forms known in phyla such as Porifera, Cnidaria, Annelida, Mollusca, Nemertea, Platyhelminthes, Arthropoda, Echinodermata, and Urochordata ${ }^{27}$. Kingsley (1984) defined "spicules" as individual minute inclusions of calcium carbonate which occur over an extended region of the animal's body. Based on the result of the EDS analysis revealing a calcium-rich composition for the rod-like inclusions of Thoracophelia minuta sp. nov., we identify the new species' rod-like inclusions as spicules. It is also important to note that the high S peak may be due to the simultaneous emission of sulphur during biomineralization since this species lives in the sand interstices, which suggests that it is susceptible to a reductive condition.

In annelids, various biominerals have been reported (Table 2). However, only three polychaete species (Echinofabricia alata, E. dubia, and E. goodhartzorum from the family Fabriciidae) have been known to possess spicules ${ }^{28}$. In opheliids, rod-like inclusions have been known in a previous study by Belova and Zhadan ${ }^{12}$. These inclusions are similar to the spicules of the new species in their shape and position in the body, except that the species observed by Belova and Zhadan ${ }^{12}$ have the inclusions growing out of cells. Further, Belova and Zhadan ${ }^{12}$ did not investigate the inclusions' composition, preventing its identification as spicules. 


\begin{tabular}{|c|c|c|c|c|}
\hline Groups & Type of materials & Position & Main minerals & References \\
\hline Amphinomidae & Chaetae & External & $\mathrm{Ca}$ & Pleijel et al. ${ }^{11}$ \\
\hline Sternaspidae & Ventral shields & External & Fe, $\mathrm{P}$ & Lowenstam $^{10}$ \\
\hline Siboglinidae & Chaetae & external & $\mathrm{Fe}, \mathrm{Mn}$ & Duperron et al. ${ }^{29}$ \\
\hline Cirratulidae & Tubes & External & $\mathrm{Ca}$ & Taylor et al. ${ }^{7}$ \\
\hline Sabellidae & Tubes & External & $\mathrm{Ca}$ & Vovelle et al. $^{8}$ \\
\hline Serpulidae & Tubes & External & $\mathrm{Ca}$ & Vinn et al. ${ }^{9}$ \\
\hline Syllidae & Granule-shaped inclusions & Internal & $\mathrm{Ca}$ & Briggs et al. ${ }^{30}$ \\
\hline Nephtyidae & Granule-shaped inclusions & Internal & $\mathrm{Ca}$ & Gibbs and Bryan ${ }^{31}$ \\
\hline $\begin{array}{l}\text { Fabriciidae } \\
\text { (Echinofabricia spp.) }\end{array}$ & Rod-shaped inclusions & Internal & $\mathrm{Ca}$ & Huang et al. ${ }^{28}$ \\
\hline $\begin{array}{l}\text { Opheliidae } \\
\text { (Ophelia spp.) }\end{array}$ & Rod-shaped inclusions & Internal & $?$ & Belova \& Zhadan ${ }^{12}$ \\
\hline $\begin{array}{l}\text { Opheliidae } \\
\text { (Thoracophelia minuta) }\end{array}$ & Rod-shaped inclusions & Internal & $\mathrm{Ca}, \mathrm{S}$ & This study \\
\hline
\end{tabular}

Table 2. List of biomineralized materials in annelids.

The molecular phylogenetic tree generated in this study confirmed that our spicule-possessing species, Thoracophelia minuta sp. nov., is nested in Opheliidae (Fig. 4). Opheliidae and Fabriciidae, the other family with spicule-possessing species, have never been grouped together in a clade ${ }^{1}$. Recent phylogenetic studies based on expressed sequence tag (EST) libraries also indicated that these two families do not form a clade ${ }^{32,33}$. These results indicate that spicules were acquired at least twice in Sedentaria, Annelida (Table 2). In the present study, the SEM-EDS identified the spicules' elemental composition and molecular phylogenetic analysis revealed the phylogenetic position of the new spicule-bearing species. However, to unravel the evolution of biomineralisation in Annelida, comparative histological studies of the biomineral-producing cells using a transmission electron microscope and further investigation for taxa with biominerals are necessary.

In addition to the distribution of biominerals in annelids, miniaturisation that took place in the new species might be noteworthy to understand the evolutionary significance of acquiring spicules. The new species have a minute body, unlike all other known species of Thoracophelia. In the molecular tree, the new species forms a clade with T. ezoensis, a species described from the same area (Hokkaido, Japan) as the new species ${ }^{34}$. The other Thoracophelia clade consists of T. mucronata, T. williami, and T. dillonensis, all collected from the same area of Dillon Beach, USA. It is likely that the new species speciated around the Sea of Japan from the ancestral species of the T. minuta-T. ezoensis clade. The most conservative view is that the ancestral species is a large species like all known species of Thoracophelia, except for the new species, and miniaturisation occurred in this species. In annelid taxa, two hypotheses of miniaturising evolution have been reported: progenesis or stepwise miniaturisation ${ }^{35}$. For T. minuta sp. nov., progenesis is the more plausible of these two hypotheses. Progenesis theory holds that larval or juvenile stages of a larger ancestor has temporarily ceased somatic cell development and become sexually mature. ${ }^{36}$ Unlike the larger congeners, the new species have simple branchiae and four pygidium papillae, which are characters only known from a young worm of T. mucronat ${ }^{37}$. These morphological similarities with the juvenile support progenetic evolution of T. minuta sp. nov. Considering that some interstitial taxa acquired spicules (e.g., Bertiliellidae in Platyhelminthes, Rhodopemorpha in Molluscs) ${ }^{38,39}$, this progenetic evolution may have driven the acquisition of spicules in the new species as well. The most closely related taxa $T$. ezoensis inhabits similar environments and areas as this new species ${ }^{34}$, and how this speciation and progenetic evolution occurred, is yet to be studied.

\section{Conclusions}

In this study, we described Thoracophelia minuta sp. nov. that has black-rod shaped spicules. We found that the spicules contain high $\mathrm{Ca}$ and are distributed in the coelomic cavity. The new species has a minute body unlike other opheliid congeners. Our phylogenetic analysis indicated that progenetic evolution occurred in the new species. The relationship between this progenetic evolution ( $\approx$ interstitial life) and spicule evolution is still unclear. Further case studies are needed to understand the evolution of spicules in annelids.

Received: 12 June 2020; Accepted: 24 December 2020

Published online: 15 January 2021

\section{References}

1. Rouse, G. \& Pleijel, F. Polychaetes. 354 (Oxford University Press, New York, 2001).

2. Simkiss, K. \& Wilbur, K. M. Biomineralization. 377 (Academic Press, San Diego, 1989).

3. Kawasaki, K., Buchanan, A. V. \& Weiss, M. Biomineralization in Humans: making the hard choices in life. Annu. Rev. Genet. 43, 119-142 (2009).

4. Murdock, D. J. E. The 'biomineralization toolkit' and the origin of animal skeletons. Biol. Rev. 95, 1372-1392 (2020).

5. Knoll, A. H. Biomineralization and evolutionary history. Rev. Mineral. Geochem. 54, 329-356 (2003).

6. Luo, Y.-J. et al. The Lingula genome provides insights into branchiopod evolution and the origin of phosphate biomineralization. Nat. Commun. 6, 8301 (2015). 
7. Taylor, P. D., Vinn, O., Kudryavtsev, A. \& Schopf, J. W. Raman spectroscopic study of the mineral composition of cirratulid tubes (Annelida, Polychaeta). J. Struct. Biol. 171, 402-405 (2010).

8. Vovelle, J., Rusaouen-Innocent, M., Grasset, M. \& Truchet, M. Halogenation and quinone-taning of the organic tube components of some Sabellidae (Annelida Polychaeta). Cah. Biol. Mar. 35, 441-459 (1994).

9. Vinn, O., Ten Hove, H. A., Mutvei, H. \& Kirsimäe, K. Ultrastructure and mineral composition of serpulid tubes (Polychaeta, Annelida). Zool. J. Linn. Soc. 154, 633-650 (2008).

10. Lowenstam, H. A. Phosphatic hard tissues of marine invertebrates: their nature and mechanical function, and some fossil implications. Chem. Geol. 9, 153-166 (1972).

11. Pleijel, F., Rouse, G. W. \& Vannier, J. Carboniferous fireworms (Amphinomida: Annelida), with a discussion of species taxa in paleontology. Invertebr. Syst. 18, 693-700 (2004).

12. Belova, P. A. \& Zhadan, A. E. A novel type of polychaete coelomocytes found in Ophelia limacina (Rathke, 1843). Doklady Biol. Sci. 440, 313-315 (2011).

13. Law, C. J., Dorgan, K. M. \& Rouse, G. W. Validation of three sympatric Thoracophelia species (Annelida: Opheliidae) from Dillon Beach, California using mitochondrial and nuclear DNA sequence data. Zootaxa 3608, 67-74 (2013).

14. Santos, C. S. G., Nonato, E. F. \& Petersen, M. E. Two new species of Opheliidae (Annelida: Polychaeta): Euzonus papillatus sp. $\mathrm{n}$. from a northeastern Brazilian sandy beach and Euzonus mammillatus sp. $\mathrm{n}$. from the continetal shelf of south-eastern Brazil. Zootaxa 478, 1-12 (2004).

15. Jimi, N. \& Fujiwara, Y. New species of Trophoniella from Shimoda, Japan (Annelida, Flabelligeridae). ZooKeys 614, 1-13 (2016).

16. Carr, C. M., Hardy, S. M., Brown, T. M., Macdonald, T. A. \& Hebert, P. D. A tri-oceanic perspective: DNA barcoding reveals geographic structure and cryptic diversity in Canadian polychaetes. PLOS ONE 6, e22232 (2011).

17. Medlin, L., Elwood, H. J., Stickel, S. \& Sogin, M. L. The characterization of enzymatically amplified eukaryotic 16S-like rRNAcoding regions. Gene 71, 491-499 (1988).

18. Lenaers, G., Maroteaux, L., Michot, B. \& Herzog, M. Dinoflagellates in evolution. A molecular phylogenetic analysisof large subunit ribosomal RNA. J. Mol. Evol. 29, 40-51 (1989).

19. Paul, C., Halanych, K. M., Tiedemann, R. \& Bleidorn, C. Molecules reject an opheliid affinity for Travisia (Annelida). Syst. Biodivers. 8, 507-512 (2010).

20. Katoh, K. \& Standley, D. M. MAFFT multiple sequence alignment software version 7: improvements in performance and usability. Mol. Biol. Evol. 30, 772-780 (2013).

21. Capella-Gutiérrez, S., Silla-Martínez, J. M. \& Gabaldón, T. trimAL: a tool for automated alignment trimming in large-scale phylogenetic analysis. Bioinformatics 25, 1972-1973 (2009).

22. Tanabe, A. S. Kakusan: a computer program to automate the selection of a nucleotide substitution model and the configuration of a mixed model on multilocus data. Mol. Ecol. Notes 7, 962-964 (2007).

23. Stamatakis, A. RAxML-VI-HPC: maximum likelihood-based phylogenetic analyses with thousands of taxa and mixed models. Bioinformatics 22, 2688-2690 (2006).

24. Ronquist, F. et al. MRBAYES 3.2: efficient Bayesian phylogenetic inference and model selection across a large model space. Syst. Biol. 61, 539-542 (2012).

25. Rambaut, A., Drummond, A. J., Xie, D., Baele, G. \& Suchard, M. A. Posterior summarisation in Bayesian phylogenetics using Tracer 1.7. Syst. Biol. syy032 (2018).

26. Misaka, T. \& Sato, M. A new species of Euzonus (Polychaeta: Opheliidae) from subtidal zones in Japan. Zool. Sci. 20, 1171-1177 (2003).

27. Kingsley, R. J. Spicule formation in the invertebrates with special reference to the gorgonian Leptogorgia virgulata. Am. Zool. 24, 883-891 (1984).

28. Huang, D., Fitzhugh, K. \& Rouse, G. W. Inference of phylogenetic relationships within Fabriciidae (Sabellida, Annelida) using molecular and morphological data. Cladistics 27, 356-379 (2011).

29. Duperron, S., Gaudron, S.M., Lemaitre, N. \& Bayon, G. A microbiological and biogeochemical investigation of the cold seep tubeworms Escarpia southwardae (Annelida: Siboglinidae): symbiosis and trace element composition of the tube. Deep-Sea Res. I 190, 105-114.

30. Briggs, R. T., Chaffee, J. \& Anderson, M. Calcium-containing granules in myoepithelial cells of the polychaete Syllis spongiphila: possible ioninc modulators. Tissue Cell 17, 923-928 (1985).

31. Gibbs, P. E. \& Bryan, G. W. Calcium phosphate granules in muscle cells of Nephtys (Annelida, Polychaeta) - a novel skeleton?. Nature 310, 494-495 (1984).

32. Andrade, S. C. S. et al. Articulating "Archiannelids": phylogenomics and annelid relationships, with emphasis on meiofaunal taxa. Mol. Biol. Evol. 32, 2860-2875 (2015).

33. Weigert, A. \& Bleidorn, C. Current status of annelid phylogeny. Org. Divers. Evol. 16, 345-362 (2016).

34. Okuda, S. Description of a new sedentary polychaete, Thoracophelia ezoensis n. sp. Proc. Imper. Aca. 12, 201-202 (1936).

35. Struck, T. H. et al. The evolution of annelids reveals two adaptive routes to the interstitial realm. Curr. Biol. 25, 1-7 (2015).

36. Westheide, W. Progenesis as a principle in meiofauna evolution. J. Nat. His. 21, 843-854 (1987).

37. Dales, P. The larval development and ecology of Thoracophelia mucronata (Treadwell). Biol. Bull. 102, 232-242 (1952).

38. Rieger, R. M. \& Sterrer, W. New spicular skeletons in Turbellaria, and the occurrence of spicules in marine meiofauna. J. Zool. Syst. Evol. Res. 13, 207-278 (1975).

39. Wilson, N. G., Jörger, K. M., Brenzinger, B. \& Schrödl, M. Phylogenetic placement of the enigmatic worm-like Rhodopemorpha slugs as basal Heterobranchia. J. Mollus. Stud. 83, 399-408 (2017).

\section{Acknowledgements}

We are grateful to Ms. Natsumi Hookabe and Dr. Hiroshi Kajihara for their generous help in sampling. Energydispersive spectroscopy observations were supported by Dr. Kenji Horie. This study was partly supported by JSPS KAKENHI No. JP1900160 to NJ. We would like to thank Editage (www.editage.com) for English language editing. This study was performed using facilities of National Institute of Polar Research (NIPR).

\section{Author contributions}

N.J. and S.F. collected samples and wrote the main manuscript text. M.T. conducted SEM-EDS analysis. S.I. improved the main manuscript. All authors reviewed the manuscript.

\section{Competing interests}

The authors declare no competing interests.

\section{Additional information}

Correspondence and requests for materials should be addressed to N.J. 
Reprints and permissions information is available at www.nature.com/reprints.

Publisher's note Springer Nature remains neutral with regard to jurisdictional claims in published maps and institutional affiliations.

(c) (i) Open Access This article is licensed under a Creative Commons Attribution 4.0 International License, which permits use, sharing, adaptation, distribution and reproduction in any medium or format, as long as you give appropriate credit to the original author(s) and the source, provide a link to the Creative Commons licence, and indicate if changes were made. The images or other third party material in this article are included in the article's Creative Commons licence, unless indicated otherwise in a credit line to the material. If material is not included in the article's Creative Commons licence and your intended use is not permitted by statutory regulation or exceeds the permitted use, you will need to obtain permission directly from the copyright holder. To view a copy of this licence, visit http://creativecommons.org/licenses/by/4.0/.

(C) The Author(s) 2021 